P819 INFLUENCE OF KNOWLEDGE, ATTITUDE, MOTIVATION ON WILLINGNESS OF MOTHERS FOR THEIR DAUGHTERS TO UNDERGO HPV VACCINATION

Sybil Lizanne Bravo*. University of the Philippines, Obstetrics and Gynaecology, Manila, Philippines

\subsection{6/sextrans-2019-sti.865}

Background Cervical cancer is second leading cancer and cause of morbidity/mortality among Filipinas. Human papillomavirus (HPV) is a necessary cause of cervical cancer. A primary mode of prevention is use of vaccines. Before vaccinations are implemented, sociocultural issues should be addressed. The aim was to determine association of knowledge, attitude and motivational factors of mothers on their willingness for their daughters (aged 9-13 years) to undergo vaccination.

Methods This was a cross-sectional study with a pretested and validated survey given to 352 mothers.

Results $97.18 \%$ of women were willing to have the vaccine for their children. One-third of mothers had high knowledge on use of vaccines (34.93\%). Women who reached college, had youngest child 11 - 13 years, with annual income $\geq$ PHP 60,000 , non-Catholic, and who never to a few times/ year attended Church had higher knowledge. More believed getting the vaccine would not affect girl's sexual activity. Most agreed they were not viewed as bad parents. There were agreeing responses from positive attitude, and more disagreeing responses in negative attitude $(\mathrm{p}=0.01)$. More mothers agreed cost was prohibitive, with giving 2 doses, and were willing to follow doctors' recommendations. There was no difference in agreeing responses between positive and negative motivating factors $(p=0.79)$. Likelihood of willingness on vaccination was twice as knowledge score and scores on positive attitude items increased. Odds of willingness increased as scores on negative attitude decreased.

Conclusion Role of knowledge and attitudes on negative perceptions on the vaccine were important predictors of willingness of mothers toward vaccination. In developing countries such as ours, there is strong need to increase knowledge of HPV, cervical cancer, and prophylactic vaccines to increase willingness of Filipino mothers to have their daughters immunized. Physicians and government agencies should put priority on HPV vaccination, making concerted efforts to decrease negative attitudes.

Disclosure No significant relationships.

\section{P821 SEXUAL BEHAVIOR IN ADOLESCENTS BEFORE AND AFTER INTRODUCTION OF THE HPV VACCINATION IN CANADA}

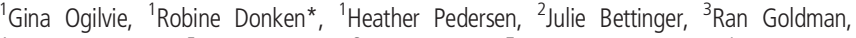
${ }^{4}$ Elizabeth Saewyc, ${ }^{5}$ Simon Dobson, ${ }^{6}$ Monika Naus, ${ }^{7}$ Manish Sadarangani. ${ }^{1}$ University of British Columbia, Vancouver, Canada; ${ }^{2} B C$ Children's Research Institute, Vancouver, Canada; ${ }^{3}$ University of British Columbia, Department of Pediatrics, Vancouver, Canada; ${ }^{4}$ University of British Columbia, School of Nursing, Vancouver, Canada; ${ }^{5}$ Sidra Medicine, Doha, Qatar; ${ }^{6}$ University of British Columbia, Faculty of Medicine, Vancouver, Canada; ${ }^{7} B C$ Children's Hospital Research Institute, Vaccine Evaluation Center, Vancouver, Canada
\end{abstract}

10.1136/sextrans-2019-sti.866

Background Currently all Canadian jurisdictions have implemented school-based human papillomavirus (HPV) vaccination into their routine immunization programs. Uptake rates in girls vary from $52.6 \%$ to $89.3 \%$ between jurisdictions. At the time of implementation, there were concerns that HPV vaccination could lead to riskier sexual health choices among adolescents. This systematic review explores the influence HPV vaccination programs on sexual behavior among adolescent girls in Canada.

Methods A systematic literature review was performed using PubMed, followed by a cited reference search. Studies were included if they reported sexual behaviors or biological outcomes in Canadian participants. We descriptively compared sexual behavior and rates of pregnancy and sexually transmittable infections (STI) in the pre- and post vaccination era or amongst vaccinated and unvaccinated.

Results In total, 38 Canadian articles were identified and four met eligibility criteria. HPV vaccination was not associated with a diagnosis of STI (OR 0.81, 95\%CI 0.63-1.04 and $0.91,95 \%$ CI $0.78-1.06$, respectively). Being eligible for HPV vaccination was not associated with pregnancy (OR 0.69 , 95\%CI $0.49-0.98$ and OR 1.01 , 95\%CI 0.93-1.10). One study found that girls eligible for HPV vaccination were less likely to ever have had sexual intercourse (OR 0.89, 95\% CI 0.82-0.98). HPV vaccination was not associated with the lifetime number of partners for vaginal or receptive anal intercourse. There was no difference in having had $\geq 3$ sexual partners within the past year. Only the lifetime number of partners for oral receptive intercourse was found to be higher among vaccinated (mean 2.50) than unvaccinated (mean 1.51) women. Use of condoms at last intercourse was slightly higher in vaccine eligible cohorts (OR 1.28, 95\%CI 1.10-1.49).

Conclusion HPV vaccination has not been associated with riskier sexual behavior, increased STI or pregnancy rates among young Canadian adolescents. These findings are in line with those from an increasing number of international studies. Disclosure No significant relationships.

\section{P822 FACTORS ASSOCIATED WITH ONCOGENIC HUMAN PAPILLOMAVIRUS PREVALENCE AMONG AUSTRALIAN WOMEN FOLLOWING VACCINE INTRODUCTION}

${ }^{1}$ Dorothy Machalek* ${ }^{1}$ Hannah Shilling, ${ }^{1}$ Steph Atchison, ${ }^{1}$ Alyssa Cornall, ${ }^{2} J u l i a$ Brotherton, ${ }^{3}$ Deborah Bateson, ${ }^{4}$ Kathleen Mcnamee, ${ }^{5}$ Jane Hocking, ${ }^{6}$ John Kaldor, ${ }^{7}$ Marcus Chen, ${ }^{7}$ Christopher Fairley, ${ }^{7}$ Eric Chow, ${ }^{8} \mathrm{~S}$ Rachel Skinner, ${ }^{1}$ Gerald Murray, ${ }^{1}$ Monica Molano, 'Sepehr Tabrizi, 'Suzanne Garland. 'The Royal Women's Hospital, Centre for Women's Infectious Disease Research, Parkville, Australia; ${ }^{2}$ VCS Population Health, VCS Foundation, East Melbourne, Australia; ${ }^{3}$ Family Planning New South Wales, Ashfield, Australia; ${ }^{4}$ Family Planning Victoria, Box Hill, Australia; ${ }^{5}$ University of Melbourne, Melbourne School of Population and Global Health, Parkville, Australia; ${ }^{6}$ University of New South Wales, The Kirby Institute for Infection and Immunity in Society, Kensington, Australia; ${ }^{7}$ Alfred Health, Melbourne Sexual Health Centre, Carlton, Australia; ${ }^{8}$ University of Sydney, Discipline of Child and Adolescent Health, Faculty of Medicine and Health, Camperdown, Australia

\subsection{6/sextrans-2019-sti.867}

Background In Australia, high and widespread uptake of the quadrivalent human papillomavirus (HPV) vaccine has led to substantial population-level reductions in the prevalence of HPV16/18 in women aged $\leq 35$ years. We assessed risk factors for oncogenic HPV detection among 18-35 year old women in 2015-2018. 